This is the author's Post-print version (final draft post-refereeing as accepted for publication by the journal). The definitive, peer-reviewed and edited version of this article is published as: van Ham M. and Mulder C.H. (2005) Geographical access to childcare and mothers' labour-force participation. Journal of Economic and Social Geography (TESG) 96, 63-74. http://dx.doi.org/10.1111/j.1467-9663.2005.00439.x

\title{
Geographical access to childcare and mothers' labour-force participation
}

\author{
MAARTEN VAN HAM* \& CLARA H. MULDER ${ }^{* *}$
}

* Utrecht University, Faculty of Geosciences, Urban and Regional research Centre Utrecht (URU), P.O. Box 80.115, 3508 TC, The Netherlands, Phone +31 (0)30 253 1399, Fax +31

(0)30 253 2037, email: m.vanham@ geog.uu.nl

**University of Amsterdam, Department of Geography and Planning, Amsterdam Institute for Metropolitan and International Development Studies (AMIDSt), Nieuwe Prinsengracht 130, 1018VZ Amsterdam, The Netherlands, fax +31 20 5254051, e-mail: c.h.mulder@uva.nl

\begin{abstract}
This article addresses the question whether geographical access to institutionalized childcare influences mothers' labour-force participation in the Netherlands. The conceptual framework of the article is based on a time-geographic perspective on female labour-force participation. According to this perspective, women are faced with severe day-to-day space-time constraints that form a spatial barrier to labour-force participation. It is argued that, for many mothers with pre-school aged children, access to employment opportunities is partly determined by geographical access to childcare facilities. Using data from the Netherlands Housing Demand survey and a detailed measure of geographical access to childcare, it is shown that, for mothers with young children, the probability of being engaged in paid employment increases as the number of day-care slots per 100 children in the residential area increases. In the regression model, the effect of access to childcare on mothers' labour-force participation is estimated after individual, household, and local labour market characteristics are controlled for.
\end{abstract}

Key words: female labour-force participation, childcare, time-space constraints, geographical access, GIS

\section{INTRODUCTION}

Having access to affordable, quality childcare is important for parents seeking to match their care commitments to young children with their own preferences for participating in the labour market. Access to childcare is much more important for the employment opportunities of mothers than for fathers. Several studies have shown that, despite changes in gender roles in the last few decades, women are still primarily responsible for most household and childcare responsibilities, even when both spouses have a paid job (SCP 1999; Moen 2003). For many mothers, childcare is essential when combining a paid job with having children: being unable to use childcare facilities is thought to force mothers out of the labour market, or to work parttime (OECD 2002). 
Most research on the effects of the provision of childcare on mothers' labour-force participation focuses on the affordability of childcare (see, for example, Berger \& Black 1992; Blau \& Robbins 1988, 1989, 1991; Blau \& Hagy 1998; Connely 1991, 1992). Following Heckman (1974), the costs of childcare are usually treated as a reduction in female wages. The underlying idea is that, if a large share of the income generated by paid employment has to be spent on childcare, working is simply not worthwhile. Most of the empirical tests that have set out to investigate the relationship between the costs of childcare and mothers' labourforce participation have found the expected negative association.

Given the fact that most existing research on the effect of childcare on mothers' labour-force participation has a background in labour economics, the focus on affordability of childcare is understandable. However, if mothers are to be able to use childcare, it should be not only affordable, but also available. Several authors have suggested that geographical access to childcare facilities is an important factor determining access to employment opportunities for mothers with young children (see Truelove 1996; Kwan 1999a 1999b). Mothers with good geographical access to childcare facilities can be expected to have more opportunities to combine having children with a paid job and therefore participate more often on the labour market. Only a few studies have actually included some measure of geographical access to childcare in their models. For the Netherlands, Van Dijk and Siegers (1996) found a positive effect of the availability of childcare in the municipality of residence on female labour participation using 1988 data. For Germany, Kreyenfeld and Hank (2000) found no effect, while Büchel and Spiess (2002) found a positive effect using data from the same panel study.

The Netherlands market for childcare is characterized by a high level of government regulation in contrast with, for example, the United States market for childcare, where market forces prevail. The Netherlands government provides a large share of the childcare facilities and government-pricing policies ensure that parents pay roughly the same amount for institutionalized childcare throughout the country (Van Dijk \& Siegers 1996). Although geographical variation in financial barriers to institutionalized childcare facilities is slight, geographical variation in their availability is substantial (NUK 2001). Geographical differences in demand alone are not capable of explaining childcare provision's geographical variation; it is also caused by differences in the budgetary priorities of the municipal councils providing (most of) the care (Turksema 2000).

This article addresses the question whether geographical access to institutionalized childcare influences mothers' labour-force participation in the Netherlands. The article contributes to the existing empirical studies in two ways. First, by conceptualizing the mechanism by which geographical access to childcare influences mothers' labour force participation. By applying a time-geographic perspective, geographical access to childcare is placed in a broader framework of geographical barriers to female labour-force participation. Second, by using a detailed measure of geographical access to childcare to test whether access influences mothers' labour-force participation. In the empirical part of the paper, the focus is on institutionalized childcare alone.

Geographical access to childcare is included in the empirical model directly by measuring the number of institutionalized childcare slots per 100 children in the age range 0 to 4 within 10 minutes' travel from the residence (calculated by means of a geographical information system). The data on childcare provision come from the Monitoring Agency Childcare Provision (Netwerkbureau Uitbreiding Kinderopvang). The individual level data we have used come from the 1998 Netherlands Housing Demand Survey (WoningBehoefte Onderzoek), which includes detailed information on individual and household characteristics for almost 120,000 respondents. In the empirical model, the effect of geographical access to childcare on the mother's employment status is estimated using logistic regression. 


\section{TIME-SPACE CONSTRAINTS, CHILDCARE AND LABOUR-FORCE PARTICIPATION}

Women face severe day-to-day space-time constraints because of their domestic workload, which limits the time available for work and getting to work, (Hanson \& Pratt 1990; Pratt \& Hanson 1991). These constraints form a serious geographical barrier to labour-force participation, because they restrict the spatial opportunity set of available jobs. The tight time budget caused by gender differences in household roles is thought to be an important cause of women's orientation to the local labour market (Madden 1981; see also Johnston-Anumonwo 1992 on the household responsibility hypothesis). Empirical evidence has shown that women work closer to home than men (Blumen 1994; Gordon, Kumar \& Richardson 1989; McLafferty \& Preston 1997; Turner \& Niemeijer 1997).

For many mothers with pre-school aged children, the possibility of using childcare facilities during working hours is crucial for combining having a family with a paid job. For working women, the trip to the childcare facility draws on their limited time-space budget, which further restricts their opportunity set of available jobs. Mothers work even more close to home than women without children (see Baccaïni 1997; Rouwendal 1999). Several authors have asserted that geographical access to childcare facilities is an important factor determining access to certain job locations for women with young children (Michelson 1985, 1988; Tivers 1985, 1988; Hanson \& Pratt 1988, 1990; England 1996a, 1996b; Gilbert 1998; Kwan 1999a 1999b). This assertion implies that, for many mothers, good geographical access to childcare facilities is a precondition for access to job opportunities.

The time-geographic framework proposed by Hägerstrand (1970) provides some very useful concepts that facilitate understanding of the mechanism by which geographical access to childcare influences mothers' labour-force participation. According to Hägerstrand, time is an important constraint on our spatial behavior and influences the spatial choice sets open to us in nearly every domain of our lives. Hägerstrand identified three categories of constraints: capability, coupling, and authority. Capability constraints determine a mothers' potential daily activity space, the outer border of which is delineated by the maximum time available in a day for traveling and the mode of transport used. In principle, all jobs and childcare facilities within this potential activity space are open to a mother. However, a working mother has to fit at least a stay at her work address, a visit to the childcare facility, and the trips that connect home, work and the childcare facility in her time-space budget (see also Droogleever Fortuijn and Karsten 1989). This coupling constraint limits the possible combinations of job locations and childcare facilities. Furthermore, a combined trip from home to the childcare facility and to work is only possible when due consideration is given to working hours and the opening hours of childcare facilities. This constraint further limits the possible combinations of job locations and childcare facilities.

Together, the time-space constraints determine an individual mother's potential path area (Lenntorp 1976, 1978; Burns 1979), which contains all the possible combinations of routes she can traverse while traveling between home, potential work locations, and childcare facilities. The greater the number of childcare facilities available to a mother within her potential daily activity space, the greater is the number of potential paths, and the greater the probability that she can find a combination of work location and childcare facility location that fits her time-space budget.

The best locations for childcare facilities are very close to home, very close to work, and on the way from home to work. For some mothers, using childcare close to work is the most convenient, because the coordination of working times with the opening times of the 
childcare facility is easiest. However, we think that a measure of geographical access to childcare from the residence better measures the choice set of childcare facilities than a measure from the workplace, for three reasons. First, the location of the residence is more stable than the work location. Second, we also include in the analysis mothers without employment and for them the workplace is not defined. And third, for couples with a less gendered division of childcare tasks, childcare near home is most convenient, because it is within reach for both partners.

We therefore hypothesized that mothers with good geographical access to childcare from their residential location have a greater probability of being engaged in paid employment than mothers with poor geographical access to childcare facilities.

\section{Other determinats of mother's labour-force participation}

It is argued above that geographical access to childcare facilities partly determines a mother's access to employment opportunities. Whether mothers actually find a job depends however on local labour market characteristics. Van Ham (2002) has shown that having good geographical access to suitable employment from the residence positively influences individual labour market outcomes and leads to a greater probability of being in paid employment and better jobs for those in employment. Mothers with good geographical access to suitable employment are therefore expected to be more likely to be engaged in paid labour than mothers with poor access to employment opportunities.

The probability of being engaged in paid employment can also be expected to vary with a mother's age. Many women stop working after giving birth and do not re-enter the labour market for a few years. This practice leads to the expectation that the probability of mothers being engaged in paid employment rises with age. There are however other reasons for expecting a negative effect of a mother's age on her labour-force participation. Mothers from older cohorts grew up with more traditional ideas of gender roles than mothers from younger cohorts. Older mothers can therefore be expected to be in paid employment less often than younger mothers (Van Dijk \& Siegers 1996). Furthermore, mothers who have children at a later age are more likely to have health problems related to pregnancy and childbirth, which negatively influences their labour-force participation (Henkens, Meijer \& Siegers 1993; Henkens, Grift \& Siegers 2002).

Highly educated mothers will have invested more in their formal human capital than less well educated mothers. Highly educated mothers can therefore be expected to be more likely than less well educated mothers to be in paid employment (Becker 1962).

Bringing up two children takes more time than bringing up one child and makes the combination of work and family even more difficult. Mothers with more than one dependent child can therefore be expected to have a lower probability of being in paid employment than mothers with only one child. Furthermore, the total costs of childcare rise when there are more children in the household. For these reasons, mothers with more than one dependent child can be expected to have a lower probability of being engaged in paid labour than mothers with only one dependent child.

Single mothers have no partner within the household to share childcare and household responsibilities. This seriously restricts their freedom to be active on the labour market (See also Kwan 1999a 1999b). Because single mothers have only one potential income, they might find care too expensive to buy. Furthermore, single mothers in the Netherlands can count on a relatively generous social security system, so there should be no necessity to be in paid employment for purely financial reasons. Single mothers can therefore be expected to have a lower probability of being engaged in paid employment than married or cohabiting mothers.

With regard to income, mothers with a working partner, or mothers with alternative sources of income, have less need to engage in paid employment for financial reasons. It can 
therefore be expected that the greater the additional household income, the lower the probability a mother has of being engaged in paid employment.

In the Netherlands, almost $30 \%$ of the employed women who gave birth to their first child in 1997 stopped working for at least some period of time (CBS 2000). Some of these mothers do not want to combine having children with a labour career, because they give priority to bringing up their children themselves. Having a more traditional view on the upbringing of children can be expected to influence the decision not to combine careers. Such a traditional view can be expected among religious mothers, or mothers born outside the Netherlands in countries with more traditional values.

\section{DATA AND METHODOLOGY}

The data used were taken from the Netherlands Housing Demand Survey (WBO) conducted in 1998 by Statistics Netherlands among a sample of some 120,000 individuals (CBS 1999). The research population is representative of the Dutch population aged 18 and over and not living in an institution. The dataset includes detailed information on labour participation, household structure, and location of residence according to postal code area.

The research population consists of mothers with children in the age group 0 to 6 years old. Although most children in the Netherlands go to school at the age of 4, it was decided also to include mothers with children aged 5 and 6 . The underlying idea was that mothers who do not have a paid job because of poor geographical access to childcare facilities would need some time to return to the labour market. It is therefore plausible that an effect of poor geographical access to childcare is still measurable in the first years of children going to school.

Disabled mothers were excluded from the research population. The result was a total of 9,894 mothers, just over half of whom were in paid employment for more than 12 hours a week. The limit of 12 hours a week as a minimum for being in paid employment was set, because in order to be able to measure an effect of geographical access to institutionalized childcare a mother needs to have a substantial job. A mother working for less than 12 hours a week may use more informal forms of childcare as an alternative to the institutionalized childcare included in the analysis.

\section{Description of variables}

Table 1 presents the summary statistics and definitions of the variables used in this study. The dependent variable indicates whether or not the mothers in the analysis have paid employment for more than 12 hours a week.

The main independent variable is geographical access to childcare. The data on institutionalized childcare per municipality comes from the Monitoring Agency Childcare Provision (Netwerkbureau Uitbreiding Kinderopvang; see NUK 2001). In the dataset, data on the number of day-care slots for children in the age range 0 to 4 was available for 1998, the same year as the individual data from the Netherlands Housing Demand Survey (WBO). In the Netherlands, in 1998 more than 70,000 slots were available; they were used by more than 130,000 children. On average, each slot was used by 1.9 children, which indicates that most mothers used day-care for only a few days a week (NUK 2001).

Geographical access to childcare is determined by the number of childcare slots within a mother's potential daily activity space, the outer border of which is delineated by the maximum time available for traveling and the mode of transport used (see Truelove 1993 for an overview of measures). Two factors are important. The first is the location of the residence vis-à-vis the spatial configuration of childcare facilities. Because childcare facilities are not 
evenly spread over space, given a certain traveling time, different residential locations lead to different opportunity sets of childcare facilities. The second factor is the time mothers have available for traveling to the childcare facility. As stated earlier, for many mothers wanting a paid job, this time is extremely limited. Because a mother has to combine the trip to her job with a trip to the childcare facility, its ideal location would be between the home and the work location. More than $50 \%$ of the working population in the Netherlands has a single trip to work that takes less than 15 minutes (Van Ham 2002). It was therefore decided to measure all childcare slots within 10 minutes' traveling time from residential locations (see also Truelove 1996). The absolute number of childcare slots within reach says little about the availability, so geographical access to childcare was measured relative to the number of children in the age group 0 to 4 living within the 10-minute area. The data on the number of children per age group comes from Statistics Netherlands (CBS 2003).

To calculate the geographical access to childcare variable, for each municipality the number of child-care slots was distributed over the postal code areas in the municipality (weighted by the distribution of inhabitants). There are almost 4000 postal code areas in the Netherlands with an average size of just over 10 square kilometers. The redistribution was done in order to minimize possible measurement errors on the municipality level (Van Ham 2002). We are aware of the fact that this method will introduce some error in our measure of geographical access to childcare. It would be preferable to have data with the precise addresses of childcare facilities since this would make it possible to use a point-to-point travel time to calculate access. Reliable data on this low spatial level is unfortunately not available.

To determine the weighted number of childcare slots within 10 minutes a matrix of traveling times by car over the road network between the centroids of all 4000 postal code areas was calculated using the network oriented GIS extension Flowmap (De Jong \& Floor 1993). The road network used includes data on average driving speeds per road segment. Next, for each postal code Flowmap identified all other postal codes whose centroids were within 10 minutes traveling time by car over the road network (a proximity count) and added up all the children aged between 0 and 4 years old living in this area. Then, the number of childcare slots in each postal code area was divided by the number of children within 10 minutes' travel time (the slots were weighted for the number of potential users). And finally, the number of weighted childcare slots within 10 minutes' travel time was calculated with Flowmap and multiplied by 100 . The resulting variable measures the number of day-care slots per 100 children in the age group 0 to 4 in the area that can be reached by car from the center of each postal code area within 10 minutes. This variable was linked to the respondents from the Netherlands Housing Demand Survey (WBO) based on their postal code of residence.

Figure 1 shows the spatial variation in geographical access to childcare in 1998. Large differences in geographical access within 10 minutes can be observed, from less than 3 slots per 100 children to more than 35 slots per 100 children. The best balance between slots and children can be found in the urbanized areas of the country.

Please insert Figure 1 about here-

Besides the main independent variable (geographical access to childcare), several control variables are included in the analysis. The job access variable measures the number of jobs, by job level, that can be reached from the residence by car in 15 minutes or less. It was decided to use job access within 15 minutes, because more than $50 \%$ of the working population in the Netherlands has a single trip to work of 15 minutes or less (Van Ham 2002) and mothers can be expected to be overrepresented in this group (see Baccaïni 1997; 
Rouwendal 1999). The data on job opportunities were derived from the National Information System of Employment (LISA) for 1991 and 1994, and the Netherlands Labour Force Surveys (EBB) for 1994, 1995, and 1996, conducted by Statistics Netherlands (CBS 1997) The measure of job access was calculated with the GIS extension Flowmap (De Jong \& Floor 1993). We allotted a measure of job access to all mothers on the basis of the postal code area of residence and their level of formal education (see Van Ham, Hooimeijer \& Mulder 2001 for a detailed description of the method used).

The age of the mothers was measured in years. To account for non-linearity of the age effect, both a linear and a quadratic term of the age variable were included. Level of education was measured in five categories: primary education; lower secondary education; upper secondary education; higher vocational education; university education. The presence of more than one child under the age of 12 in the household was indicated by a dummy. Another dummy was included for single mothers. Additional household income was defined as the monthly household income minus the monthly earnings of the respondent in 1,000 euro. Whether or not a mother is categorized as an immigrant was based on the country of birth and measured by a dummy. Mothers born in Suriname, Netherlands Antilles, Turkey and Morocco are categorized as immigrants. Another dummy measures whether the mother is religious or not. Mothers attending one or more religious ceremonies per week are categorized as religious.

-Please insert Table 1 about here-

\section{Method of analysis}

Since the dependent variable in the model is dichotomous (whether or not in paid employment for more than 12 hours a week), a logistic regression model was used. Two alternative, more sophisticated models were considered before this straightforward model was chosen.

First, we considered using a multi-level model, because our data includes both individual level and postcode area level information. Ignoring the nested nature of this data could possibly lead to a violation of the standard assumption of independence of observations that underlies traditional regression models. This might lead to biased estimates of the standard errors of the coefficients, because the random disturbances in the regression are correlated (see, for example, Moulton 1990). However, the results and standard errors from a multi-level model (results not shown) did not differ substantially from the results from a simple logistic regression model. This is a result of the large number of postcodes (3949), and therefore the small number of respondents per postcode area.

Second, a model that corrects for selectivity bias was considered. Women with children in the age range 0-6 might be a selective category; it may be assumed that the selection process (having children) is related to our dependent variable (whether or not in paid employment). Women who decide to have children might be less oriented to their labour career than women who decide not to have children (yet). Analyzing participation while restricting the sample to mothers could therefore lead to biased results. A variant of Heckman's (1979) two-step selection model-Van de Ven and Van Praag's (1981) bivariate probit model with sample selection-was used to see to what extent the results were biased by selectivity of the research population (results not shown). The results did not lead us to use a more sophisticated model than simple logistic regression, since the estimates of the parameters and the standard errors remained stable. The only difference worth mentioning is the effect of education. After correction for the probability of having children, the effect of education on being in paid employment was slightly smaller compared with the model 
without correction. This difference can be explained by the effect of education on the probability of having children. The probability of having children at a certain age is smaller for women with a higher level of education than for women with a lower level of education.

\section{RESULTS}

Table 2 presents the results of the logistic regression model of the probability for mothers with children in the age range 0 to 6 of being in paid employment for more than 12 hours a week.

Good geographical access to childcare, measured as the number of childcare slots per 100 children in an area within 10 minutes' traveling from the residence, was expected to have a positive effect on the probability of being engaged in paid employment. Fully in line with our expectations, having good access to childcare increases a mother's probability of being engaged in paid employment. One extra childcare slot per 100 children increases the odds of a mother being in paid employment by $2.2 \%$. This effect is quite large in comparison with, for example, the effect of level of education on a mother's labour-force participation. Geographical access to childcare for the mothers in the model ranges from 0 to almost 30 childcare slots per 100 children (see Table 1). So the effect of having the maximum geographical access to childcare compared with the minimum is similar to the effect of an extra level of education.

As expected, having good access to employment has a positive effect on the probability of being engaged in paid employment. Mothers who live at a location from which they can reach many jobs within 15 minutes' travel time have a greater probability of being engaged in paid employment than mothers who do not.

The probability of mothers being engaged in paid employment increases initially with age and subsequently falls. Also as expected, the probability of being engaged in paid employment increases markedly with the educational level of the mother. The odds for a mother with a university degree being engaged in paid employment are almost 8 times the odds for a mother with only primary education.

In line with our hypothesis, the results show that having more than one child aged 12 years or less decreases the probability of being engaged in paid employment. Also in line with our hypothesis, the results show that single mothers have a smaller probability of being engaged in paid employment than married or cohabiting mothers. As expected, the higher the additional household income, the lower the probability that a mother works.

Surprisingly, we did not find any effect of being an immigrant mother on the probability of being employed. The effect is only significant after omitting the dummy for having more than one child from the model. So the effect of being a traditional mother influences the probability of being in paid employment via the number of children and not via being an immigrant mother. Being a religious mother has the effect one would expect on labour-force participation, also after controlling for the effect of having more than one child. Mothers who visit one or more religious ceremonies per week have a significantly lower probability of being engaged in paid employment than non-religious or less religious mothers. 


\section{DISCUSSION}

This article contributes to the existing literature on childcare and mothers' labour-force participation by focusing on geographical access to childcare rather than the costs of childcare. It is argued that, in the explanation of mothers' labour-force participation, it is important to include their geographical access to childcare, because that shapes their spatial choice set and influences their opportunities to combine childcare responsibilities with having a paid job. In the case of the Netherlands as compared with the United States, geographical access to childcare is even more relevant than spatial variation in the costs of care, becausethanks to government regulation of the childcare market - there is little spatial variation in the financial barriers to institutionalized childcare. There are, however, enormous spatial differences in the availability of institutionalized childcare facilities, so that mothers living at different locations have different geographical access to childcare facilities.

In the theoretical framework, using concepts from time-geography, geographical access to childcare is placed in a broader framework of geographical barriers to labour-force participation. It is argued that the greater the number of childcare facilities available to a mother within an acceptable traveling time from her home, the easier it is for her to find a suitable combination of work location and location of childcare facility which fits in her timespace budget and enables her to participate on the labour market. We therefore hypothesized that mothers of young children with good geographical access to childcare from the residential location have a greater probability of being engaged in paid employment than mothers with poor access to childcare facilities. The hypothesis was tested for the Netherlands for institutionalized childcare only. Fully in line with our expectations, the results of our analysis showed that good geographical access to childcare increases the probability of mothers being in paid employment. Our results showed that one extra childcare slot per 100 children on the local labour market increases the odds of a mother being in paid employment by $2.2 \%$. This effect is quite large in comparison with, for example, the effect of level of education on labour-force participation.

The inclusion of the geographical access to childcare variable may not have been optimal. We used what Kwan (1999a) refers to as a 'conventional access measure' that is based on the locational proximity of opportunities (childcare) to a single reference point (center of the postal code of residence). According to Kwan, such a measure cannot reflect interpersonal differences in geographical access to childcare, because mothers differ in their time budgets, activity patterns, and modes of transport. A more detailed measure of geographical access to childcare would require detailed information on individual potential path space; this was not available in our (or most other) data. Applying more advanced measures of geographical access (to childcare) is a challenge for future research and data collection.

The finding that good geographical access to childcare positively influences mothers' labour-force participation is important for our understanding of the relationship between the spatial context and individual labour-market careers. The implication is that some locations are more suitable than others for combining having a family with having a paid job. This discrepancy may lead to more pressure on the housing market on those locations with good access to both jobs and childcare facilities. The results also imply that offering childcare facilities in residential areas may encourage mothers' labour-force participation. 


\section{Acknowledgements}

This research was supported by the Netherlands Organization for Scientific Research (NWO Aspasia grant 015.000.013). The authors express their gratitude to Serv Vinders from the Monitoring Agency Childcare Provision (Netwerkbureau Uitbreiding Kinderopvang) in The Hague for the opportunity to use the very detailed data on childcare provision in the Netherlands. The authors further express their gratitude to Childcare on-line (kinderopvangonline) for delivery of data on childcare for an earlier version of this article.

\section{REFERENCES}

BACCAÏNI, B. (1997), Commuting and residential strategies in the Île-de-France: Individual behaviour and spatial constraints. Environment and Planning A 29, pp. 1801-1829.

BECKER, G. (1962), Human capital: a theoretical and empirical analysis. Journal of Political Economy 70, pp. 9-46.

Berger, M.C. \& D.A. BLACK (1992), Child care subsidies, quality of care, and the labor supply of low-income, single mothers. Review of Economics and Statistics 74, pp. 635-642.

Blau, D.M. \& A.P. HagY (1998), The Demand for Quality in Child Care. Journal of Political Economy 106, pp. 104-146.

Blau, D.M. \& P.K. RobBins (1988), Child care costs and family labor supply. Review of Economics and Statistics 70, pp. 374-381.

BlaU, D.M. \& P.K. RobBins (1989), Fertility, employment, and child care costs. Demography 26, pp. 287-299.

BLAU, D.M. \& P.K. RobBins (1991), Child care demand and labor supply of young mothers over time. Demography 28, pp. 333-351.

Blumen, O. (1994), Gender differences in the journey to work. Urban Geography 15, pp. 223-245.

BÜCHEL, F. \& C.K SPIESS (2002), Kindertageseinrichtungen und Müttererwerbstätigkeit Neue Ergebnisse zu einem bekannten Zusammenhang (Childcare and mothers' labourforce participation - New results). Vierteljahrshefte zur Wirtschaftsforschung 71, pp. 95-113.

BURNS, L.D. (1979), Transportation, temporal, and spatial components of accessibility. Lexington, MA: Lexington Books.

CBS (1997), Enquête Beroepsbevolking 1996 (Labour Force Survey 1996). 's-Gravenhage: Sdu.

CBS (1999), WoningBehoefte Onderzoek 1998 (Housing Demand Survey 1998). 'sGravenhage: Sdu.

CBS (2000), Werkende moeders (Working mothers). INDEX 5, pp. 26-27.

CBS (2003), Statline. Voorburg/Heerlen: Centraal Bureau voor de Statistiek.

CONNELY, R. (1991), The importance of child care costs to women's decision making. In: D.M. BlaU, ED., The economics of Child Care, pp. 87-118. New York: Sage Foundation.

CONNEly, R. (1992), The effect of child care costs on married women's labor force participation. The Review of Economics and Statistics 74, pp. 83-90.

DE Jong, T. \& H. FloOR (1993), Flowmap: een programma voor het weergeven en analyseren van interactiegegevens (Flowmap: a software package for displaying and analysing interaction data). Planning, methodiek en toepassing 44, pp. 16-31. 
DroOGLEEVER FortuiJn, J. \& L. KARSTEN (1989), Daily activity patterns of working parents in the Netherlands. Area 21, pp. 365-376.

ENGLAND, K. (1996a), Mothers, wives, workers: The everyday lives of working mother. In: K. EnGland, ed., Who Will Mind the Baby?, pp. 109-122. London: Routledge.

ENGLAND, K. (1996b), Who will mind the baby? In: K. ENGLAND, ed., Who Will Mind the Baby?, pp. 3-19. London: Routledge.

GILBERT, M.R. (1998), "Race," space, and power: the survival strategies of working poor women. Annals of the Association of American Geographers 88, pp. 595-621.

Gordon, P., A. KuMAR \& H.W. RichaRdSON (1989), Gender differences in metropolitan travel behaviour. Regional Studies 23, pp. 499-510.

HÄGERSTRAND, T. (1970), What about people in regional science? Papers of the Regional Science Association 24, pp. 7-21.

HANSON, S. \& G. PRATT (1988), Reconceptualizing the links between home and work in urban geography. Economic Geography 64, pp. 299-321.

HANSON, S. \& G. PRATT (1990), Geographic perspectives on the occupational segregation of women. National Geographic Research 6, pp. 376-399.

HeCKMAN, J. (1974), Effects of childcare programs on women's work effort. Journal of Political Economy 82, pp. 136-169.

HeCKMAN, J. (1979), Sample selection bias as a specification error. Econometrica 47, pp. 153-161.

Henkens, K., Y. GRIFT \& J. SiEgers (2002), Changes in female labour supply in the Netherlands 1989-1998: The case of married and cohabiting women. European Journal of Population 18, pp. 39-57.

HENKENS, K., L. MEIJER \& J. SIEGERS (1993), The labour supply of married and cohabiting women in the Netherlands, 1981-1989. European Journal of Population 9, pp. 331352.

JoHnSTON-ANUMONwO, I. (1992), The influence of household type on gender differences in work trip distance. The Professional Geographer 44, pp. 161-169.

KREYENFELD, M. \& K. HANK (2000), Does the availability of child care influence the employment of mothers? Findings from western Germany. Population Research and Policy Review 19, pp. 317-337.

KWAN, M-P. (1999a), Gender and individual access to urban opportunities: a study using space-time measures. Professional Geographer 51, pp. 210-227.

KWAN, M-P. (1999b), Gender, the home-work link, and space-time patterns of nonemployment activities. Economic Geography 75 (4), pp. 370-394.

Lenntorp, B. (1976), Paths in Space-Time Environments: A Time-Geographic Study of the Movement Possibilities of Individuals. Lund, Sweden: Royal University of Lund, Department of Geography.

LENNTORP, B. (1978), A time-geographic simulation model of individual activity programmes. In: T. CARLSTEIN, D. PARKES, \& N. ThrifT, eds., Human Activity and Time Geography, pp. 162-180. London, UK: Edward Arnold.

MAdDEN, J.F. (1981), Why women work closer to home. Urban Studies 18, pp. 181-194.

MCLAFFERTY, S. \& V. PRESTON (1997), Gender, race, and the determinants of commuting: New York in 1990. Urban Geography 18, pp. 192-212.

Michelson, W. (1985), From Sun to Sun: Daily Obligations and Community Structure in the Lives of Employed Women and Their Families. Totowa, NJ: Rowman \& Allanheld.

MiCHELSON, W. (1988), Divergent convergence: The daily routines of employed spouses as a public affairs agenda. In: C. ANDREW \& B.M. MiLroy, ed., Life Spaces: Gender, Household, Employment, pp. 81-101. Vancouver: University of British Columbia Press. 
Moen, P. (ed.) (2003), It's about time. Couples and Careers: Cornell University Press.

Moulton, B.R. (1990), An illustration of a pitfall in estimating the effects of aggregate variables on micro units. Review of Economics and Statistics 32, pp. 334-338.

NUK (2001), Monitor uitbreiding kinderopvang 2001 (Monitor Childcare Provision 2001). Den Haag: Netwerkbureau Uitbreiding Kinderopvang.

OECD (2002), Babies and Bosses - Reconciling Work and Family Life (Volume 1): Australia, Denmark and the Netherlands. Paris: OECD Publications.

PRATT, G. \& S. HANSON (1991), Time, space, and the occupational segregation of women: a critique of human capital theory. Geoforum 22, pp. 149-157.

Rouwendal, J. (1999), Spatial job search and commuting distances. Regional Science and Urban Economics 29, pp. 491-517.

SCP (1999), Naar andere tijden? Tijdsbesteding en tijdsordening in Nederland, 1975-1995 (To another time? Time use and time structuring in the Netherlands, 1975-1995). The Hague: Elsevier Bedrijfsinformatie.

TIVERS, J. (1985), Women Attached: The Daily Lives of Women with Young Children. London: Croom Helm.

TIVERS, J. (1988), Women with young children: Constraints on activities in the urban environment. In: J. Little, L. Peake \& P. Richardson, eds., Women in Cities: Gender and the Urban Environment, pp. 84-97. New York: New York University Press.

Truelove, M. (1993), Measurement of spatial equity. Environment and Planning C 11, pp. 19-34.

TRuelove, M. (1996), The locational context of child care centers in metropolitan Toronto. In: K. ENGLAND, ed., Who will mind the baby?: geographies of child care and working mothers, pp. 93-108. London: Routledge.

TURKSEMA, R.W. (2000), The supply of day care. Utrecht: ICS

TURNER, T. \& D.A. NIEMEIER (1997), Travel to work and household responsibility: new evidence. Transportation 24, pp. 397-419.

VAN DE VEN, W.P.M.M. \& B.M.S. VAN PRAAG (1981), The demand for deductibles in private health insurance: a probit model with sample selection. Journal of Econometrics 17, pp. 229-252.

VAN DIJK, L. \& J. SIEGERS (1996), The effect of the supply of subsidized day-care facilities on female labour supply. Labour: Review of Labour Economics and Industrial Relations 10, pp. 559-582.

VAN HAM, M. (2002), Job access, workplace mobility, and occupational achievement. Delft: Eburon.

VAN HAM, M., P. HoOIMEIJER \& C.H. MuldeR (2001), Urban form and job access: disparate realities in the Randstad. Journal of Economic and Social Geography 92, pp. 231-246. 
Table 1. Variable summary statistics and definitions.

\begin{tabular}{lrcc}
\hline & Mean & Std. Dev. & Range \\
\hline Dependent (works more than 12 hours a week) & 0.51 & & 0 or 1 \\
Access to childcare (per 100 children) & 6.20 & 3.65 & $0-29.5$ \\
Job access (in 100,000 jobs) & 0.90 & 0.98 & $0-5.48$ \\
Age (in years) & 33.38 & 4.73 & $18-46$ \\
Primary education & 0.11 & & 0 or 1 \\
Lower secondary education & 0.22 & & 0 or 1 \\
Upper secondary education & 0.47 & & 0 or 1 \\
Higher vocational education & 0.16 & & 0 or 1 \\
University education & 0.05 & & 0 or 1 \\
More than one child (under the age of 12) & 0.69 & & 0 or 1 \\
Single & 0.05 & & 0 or 1 \\
Additional income (in 1,000 euro) & 1.57 & 0.97 & $-0.91-9.93$ \\
Immigrant (based on country of birth) & 0.04 & & 0 or 1 \\
Religious (1 or more rel. cer. per week) & 0.13 & & 0 or 1 \\
& & & \\
Number of respondents $=9894$ & & & \\
\hline
\end{tabular}


Table 2. Logistic regression model of mothers being employed for more than 12 hours a week.

\begin{tabular}{lrlrr}
\hline & B & & St. Error & Exp (B) \\
\hline Access to childcare & 0.022 & $* * *$ & 0.007 & 1.022 \\
Job access & 0.057 & $* *$ & 0.027 & 1.058 \\
Age & 0.258 & $* * *$ & 0.049 & 1.295 \\
Age squared & -0.003 & $* * *$ & 0.001 & 0.997 \\
Primary education & 0 & & & \\
Lower secondary education & 0.477 & $* * *$ & 0.085 & 1.612 \\
Upper secondary education & 1.074 & $* * *$ & 0.079 & 2.928 \\
Higher vocational education & 1.908 & $* * *$ & 0.095 & 6.738 \\
University education & 2.078 & $* * *$ & 0.136 & 7.988 \\
More than one child & -0.924 & $* * *$ & 0.052 & 0.397 \\
Single & -0.749 & $* * *$ & 0.113 & 0.473 \\
Additional income & -0.242 & $* * *$ & 0.025 & 0.785 \\
Immigrant & -0.113 & & 0.118 & 0.893 \\
Religious & -1.032 & $* * *$ & 0.069 & 0.356 \\
Constant & -4.607 & $* * *$ & 0.805 & 0.010 \\
& & & & \\
Number of respondents $=9894$ & & & & \\
-2 Log likelihood $=12093$ & & & & \\
Model Chi-square $=1616, \mathrm{df}=13$, sig $=0.00$ & & & \\
$*=\mathrm{p}<0.10 ; * * \mathrm{p}<0.05 ; * * * \mathrm{p}<0.01$ & & & & \\
\hline
\end{tabular}


Figure 1. Geographical access to childcare within 10 minutes (slots per 100 children).

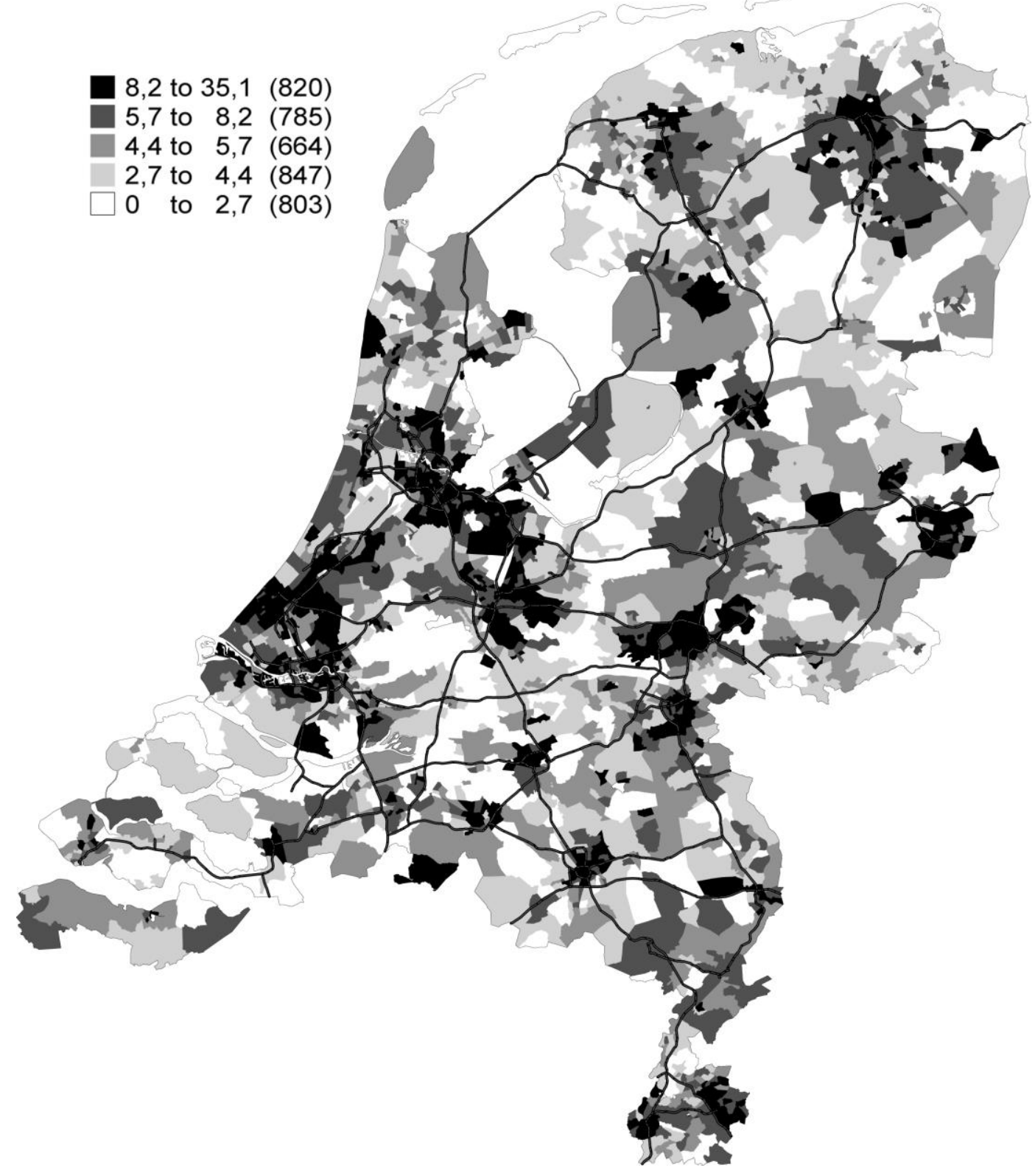

Source. Own calculations using data from Monitoring Agency Childcare Provision (NUK, 2001). 